Jurnal Pilar Teknologi, Volume 3 Nomor 2 Edisi September 2018

ISSN Print : 2502-7042 ISSN Online : 2580-3557

http://pilar.unmermadiun.ac.id

\title{
Sistem Informasi SDN Paron 02 Berbasis Web
}

\author{
Andreas Rendiana Sulistyana ${ }^{1}$, Pradityo Utomo ${ }^{2}$ \\ ${ }^{1}$ Program Studi D3 Manajemen Informatika, Universitas Merdeka Madiun, Jl.Serayu No.79 Madiun \\ E-mail: andreas_rendiana@gmail.com \\ ${ }^{2}$ Program Studi D3 Manajemen Informatika, Universitas Merdeka Madiun, Jl.Serayu No.79 Madiun \\ E-mail: pradityo@unmer-madiun.ac.id
}

\begin{abstract}
The Internet is one of the development of information technology. In this case, there are many information systems that use the internet. Information systems created using the internet are called websites. In a study conducted at Paron State Elementary School 02 will be built a web-based school information system.School information systems can help Paron State Elementary School 02 to promote information teaching and learning process in the field of education. Information system Paron 02 State Elementary School web-based this will be built using waterfall method. Waterfall method is very complex and most suitable if applied to the information system that $I$ created. The Paron 02 State Elementary Information System is built on a web-based basis. Where the system can be accessed online by the user. So the system has been built will run according to the function and the desired destination Paron State Elementary School 02. Users can find information in Paron 02 State Elementary School just by using the internet, users do not need to come to school to get information.
\end{abstract}

Keywords : SDN Paron 02 Promotion, Information System, waterfall.

\section{PENDAHULUAN}

Indonesia adalah negara yang masih dalam tahap perkembangan, tentunya dalam segala aspek dan tidak terkecuali dunia pendidikan. Saat ini kenyataan yang terjadi tentang dunia pendidikan di Indonesia masih dapat dibilang tidak terlalu baik, terutama dalam bidang pemerataan pendidikan di negara ini. Dengan dibuatnya suatu website yang berfungsi sebagai sarana promosi dan informasi kepada masyarakat tentang profil sekolah, dapat memberikan peminat untuk memilih sekolah. Dengan demikian, website ini diharapkan dapat memberikan informasi secara luas melalui internet tentang profil sekolah, proses belajar mengajar, dan informasi lainnya kepada masyarakat.

Pada penelitian ini akan dibangun sebuah sistem informasi berbasis web pada salah satu sekolah dasar di Paron. Sistem informasi sekolah merupakan sistem informasi yang dibangun untuk menangani pengelolaan dan penyajian data-datadengan lebih mudah. Penggunanya adalah seluruh elemen sekolah diantaranya kepala sekolah, guru, staff, siswa, dan wali siswa.Menurut M. Alexander dalam buku Information System Analysis: Theory and Aplication, sistem merupakan suatu grup dari elemenelemen baik yang berbentuk fisik maupun non-fisik yang menunjukkan suatu kumpulan saling berhubungan diantaranya dan berinteraksi bersama-sama menuju satu atau lebih tujuan, sasaran atau akhir dari sebuah system.

Penelitian-penelitian yang terkait memanfaatkan metode waterfall antara lain dilakukan oleh Eka Nur Ahmad Romadhoni,Triyana dan Utomo. Pada penelitian tersebut telah dibangun sistem informasi alumni SMKN 1 Jenangan di Ponorogo menggunakan metode waterfall studi kasus pengembangan. Sistem yang dibuat dapat digunakan untuk pengelolaan informasi lowongan pekerjaan agar dapat mempermudah lulusan SMKN 1 Jenangan mencari pekerjaan. Sistem telah dilakukan pengujian dan cukup sesuai dengan target yang diinginkan. Penelitian lain tentang metode waterfall juga dilakukan oleh Dermawan dan hartini, dengan mamanfaatkan metode waterfall. Dalam menganalisis dan merangcang sistem informasi perhitungan nilai mata pelajaran berbasis web pada sekolah dasar ALAzhar Syifa Budi Jatibening. Pada penelitian tersebut baru sampai tahap analisis dan perancangan sistem menggunakan Unified Modelling Language (UML), yang selanjutnyaakan dikembangkan menjadi sebuah sistem informasi. Dengan menggunakan metodologi Waterfall, perancangan sistem informasi berbasis web ini dapat meningkatkan kualitas pengolahan data informasi nilai yang sebelumnya 
menggunakan microsoft exel diubah menjadi onlinedi sekolah tersebut. Dengan menggunakan $P H P$ dan $M y S Q L$ aplikasi ini dapat dirancang dengan mudah. Dengan adanya sistem informasi ini, membantu mempermudah pengolahan data informasinilai siswa-siswi dan lebih maksimal dan praktis karena dapat di akses dari mana saja sekaligus menjaga data tetap aman. Selanjutnya Penelitian-penelitian yang terkait memanfaatkan metode waterfall dilakukan oleh Rahmawati. Pada penelitian tersebut baru sampai tahap perancangan sistem informasi sekolahsebagai sarana promosi pada MTs MA'ARIF NU 1 Ajibarang. Sistem yang dirancang yang nantinya dikembangkan menjadi sebuah sistem informasi sekolah berbasis web ini dapat dipublikasikan kepada masyarakat secara meluas, agar mampu menarik minat masyarakat untuk menuntut pendidikan di sekolah tersebut. Begitupun yang diharapkan oleh MTs Ma'arif NU 1 Ajibarang. Selanjutnya penelitan yang menggunakan metode waterfall juga dilakukan oleh Michael Abdul Rahmad. Penerapan teknologi informasi dan komunikasi diperlukan dalam dunia bisnis sebagai alat bantu dalam upaya memenangkan persaingan, dengan demikian suatu sistem yang baik harus mampu memberikan informasi yang jelas dengan data-data yang akurat dan tepat dalam proses pengolahannya. Penelitian dilakukan dengan tahapan antara lain metode pengumpulan data yang meliputi pengamatan langsung, wawancara dan kepustakaan, metode pengembangan system yang menggunakan Unified Modeling Language (UML) yang diperinci terdiri dari diagram Use case, Sequence diagram dan Activity diagram. Hasil yang didapatkan yaitu sebuah system informasi pemasaran berbasis web atau juga disebut E-Commerace yang terdiri dari halaman profile GBU18studio, halaman kategori foto, halaman cara menggunakan jasa dan halaman admin untuk pemeliharaan website. Sistem informasi pemasaran jasa foto ini dapat mempermudah dalam mempromosikan GBU18studio. Terutama untuk konsumen yang beralokasi jauh bisa mengakses informasi tentang jasa foto GBU18studio kapanpun dan dimanapun. Penelitian lain tentang metode waterfall juga dilakukan oleh Hartiwi. Sistem Informasi Penjualan dapat diartikan sebagai suatu pembuatan pernyataan penjualan, kegiatan akan dijelaskan melalui prosedur-prosedur yang meliputi urutan kegiatan sejak diterimanya pesanan dari pembeli, pengecekan barang ada atau tidak ada dan diteruskan dengan pengiriman barang yang disertai dengan pembuatan faktur dan mengadakan pencatatan atas penjualan yang berlaku. Umumnya saat ini sistem informasi penjualan yang digunakan sudah berbasis website. Website menjadi andalan dalam proses penyampaian informasi.

\section{METODE PENELITIAN}

Dalam penelitian ini yang akan dilakukan adalah membangun sistem informasi SDN Paron 02 berbasis web. Dipilih berbasis web,karena di era ini masyarakat telah mengenal internet dan hampir dalam kehidupan sehari-hari masyarakat memanfaatkan internet untuk mencari informasi dari dalam negeri maupun luar negeri. Dengan memanfaatkan internet, masyarakat tidak harus datang langsung ke sekolah hanya untuk mendapatkan informasi yang diinginkan. Sistem informasi SDN Paron 02 dibangun dengan memanfaatkan internet, bertujuan mempermudah masyarakat dalam mencari informasi tentang informasi SDN Paron 02. Adapun metode pengembangan sistem dalam membuat penelitian dapat dilihat pada Gambar 1 .

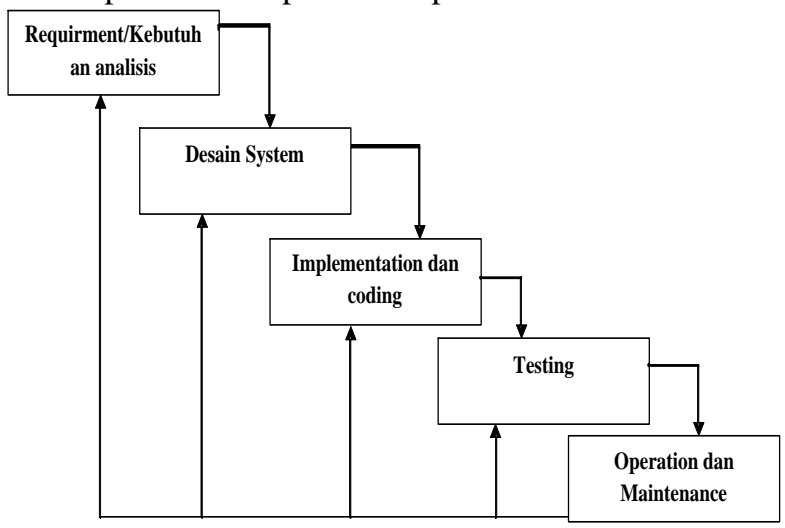

Gambar 1. Metode Waterfall.

Pada Gambar 1 telah ditunjukkan langkah-langkah yang akan dilakukan pada penelitian ini. Pada langkah Requirment Analisis dalam tahapan ini dilakukan pengumpulan data. Data diambil dengan cara menanyakan kepada Guru dan Karyawan.Pada tahap selanjutnya desain system memberikan gambaran apa yang akan dikerjakan dan merancang bagaimana tampilan nya sebelum dilakukan coding dan tahapanm selanjutnya . Di dalam tahapan ini membantu dalam menspesifikasikan hardware dan sistem serta mendefinisikan arsitektur sistem secara keseluruhan. Pada tahap selanjutnya melakukan implementation dan coding. Di dalam tahap ini dilakukan pemrogaman berupa kode-kode pembuatan software dibuat dengan terpecah, apakah sudah sesuai dengan yang diinginkan. Pada tahap selanjutnyatesting dalam melakuakan pengujian oleh pembuat aplikasi apakah sudah sesuai dengan desain dan terdapat kesalahan atau tidak. Pada tahap selanjutnya adalah operation dan maintenance. Dalam tahap ini termasuk tahapan terakhir. Software yang telah jadi dijalankan dan di lakukan pemeliharaan. Pemeliharaan termasuk dalam memperbaiki kesalahan yang tidak di temukan pada tahap sebelum nya. Perbaikan implementasi unit sistem dan peningkatan jasa sistem sebagai kebutuhan baru.

\section{HASIL DAN PEMBAHASAN}

Pada Hasil dan Pembahasan, akan dibahas hasil analisa kebutuhan, perancangan sistem, dan sistem yang telah dibuat. Untuk analisa kebutuhan, dapat dibagi menjadi 2 bagian. Bagian analisa kebutuhan yang pertama adalah analisa kebutuhan Admin, antara lain sistem terdapat layanan untuk, mengelola data user, mengelola data pelajaran, mengelola data guru,mengelola data siswadan mengelola data kelas. Analisa kebutuhan yang kedua adalah analisa kebutuhan User, antara lain sistem terdapat layanan untuk melihat data pelajaran, melihat data guru, melihat data siswa dan melihat data kelas.

Bagian analisa kebutuhan selanjutnya adalah analisa kebutuhan software, kebutuhan software untuk sistem informasi ini antara lain; System operasi Windows 7, Xampp, MySQL, PHP, Adobe dreamweaver CS3, Notepad ++, Mozilla Firefox. 
Untuk analisa kebutuhan hardware dapat menggukan komputer pribadi (PC). Spesifikasi PC yang dapat digunakan antara lain menggunakan sistem operasi windows 7, processor Intel Core i3, RAM 2 GB, Harddisk 500 GB, serta dilengkapi mouse dan keyboard.Setelah dilakukan analisa kebutuhan, kemudian dilakukan perancangan sistem. Pada penelitian ini, perancangan sistem dilakukan menggunakan DFD dan Use CaseDiagram. Adapun untuk perancangan sistemyang pertama dengan menggunakan DFD dapat ditunjukkan pada Gambar 2.

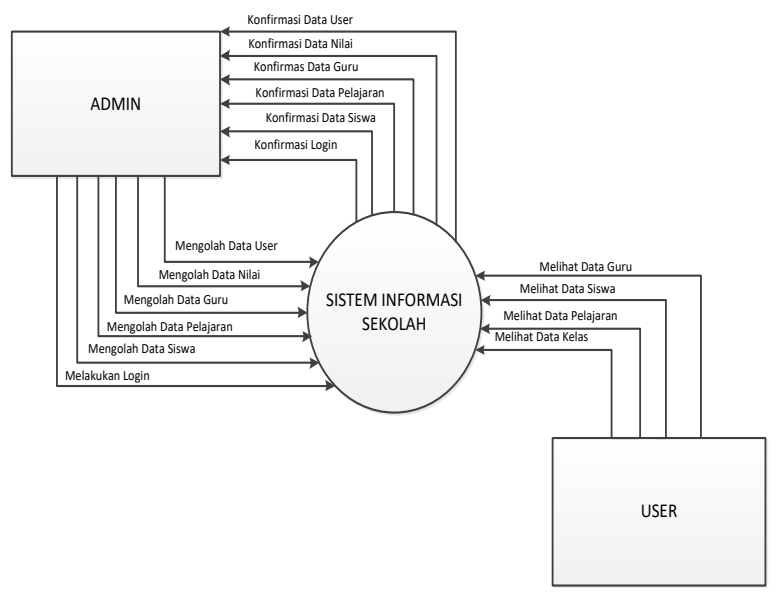

Gambar 2. DFD Level 0

Pada gambar 2. Admin melakukan login terlebih dahulu agar dapat mengelolah data yang ada, sendangkan user hanya dapat melihat data pada sistem informasi sekolah. Untuk DFD Level 1 akan digambarkan aktifitas adin yang merupakan user. Dimana admin harus login ke website dengan meng-inputkan username dan password. Kemudian username dan password tersebut di validasi. Jika username dan password valid, maka ad-min dapat login ke sistem. Sehingga, admin dapat megelola website. Diantaranya proses mengelola data guru, data siswa, data pelajaran, data kelasi dan data user. Adapun tampilan dari DFD Level 1 dapat dilihat pada Gambar 3.

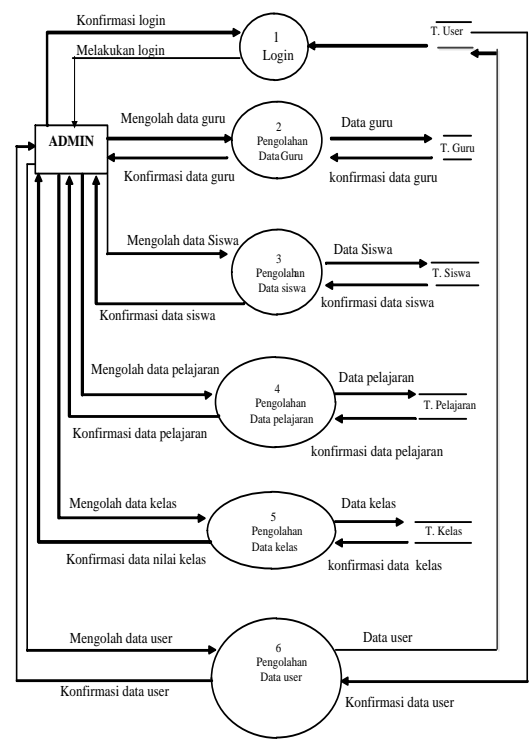

Gambar 3. DFD Level 1
Perancangan Sistem juga dibuat menggunakan Relasi Tabel. AdapunRelasi Tabel SistemInformasi SDN Paron 02 berbasis web dapat dilihat pada Gambar 4.

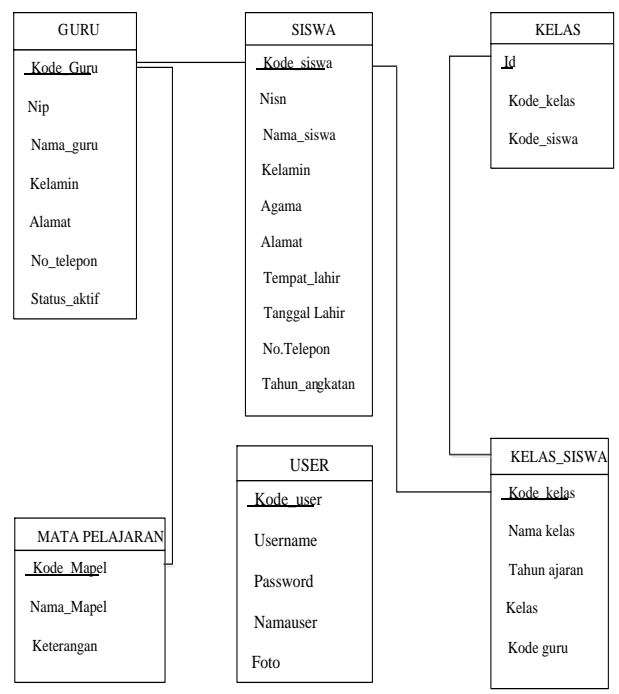

Gambar 4. Relasi Tabel

Setelah dilakukan perancangan, akan dilakukan implementasi sistem. Sistem yang dibuat berbasis web.Pada SDN PARON 02 belum ada Sistem Informasi Sekolah berbasis web yang dimiliki secara komputerisasi, dimana pada saat melakukan input data masih dilakukan secara manual. Sehingga admin mengalami kesulitan saat menginput-an data siswa, data guru, data pelajajaran, data nilai, dengan jumlah yang banyak.Tujuan dari dibuat Sistem Informasi SDN Paron 02 berbasis web, diharapkan supaya masyarakat dapat mengakses secara cepat untuk memperoleh informasi. Halaman website dibagi menjadi 2 yaitu, halaman User dan Admin.

Implementasi halaman awal sebagai user ketika memulai membuka aplikasi terdapat menu pilihan login, data pelajaran, data guru, data siswa dan data kelas. Seperti pada tampilan Gambar 5. 


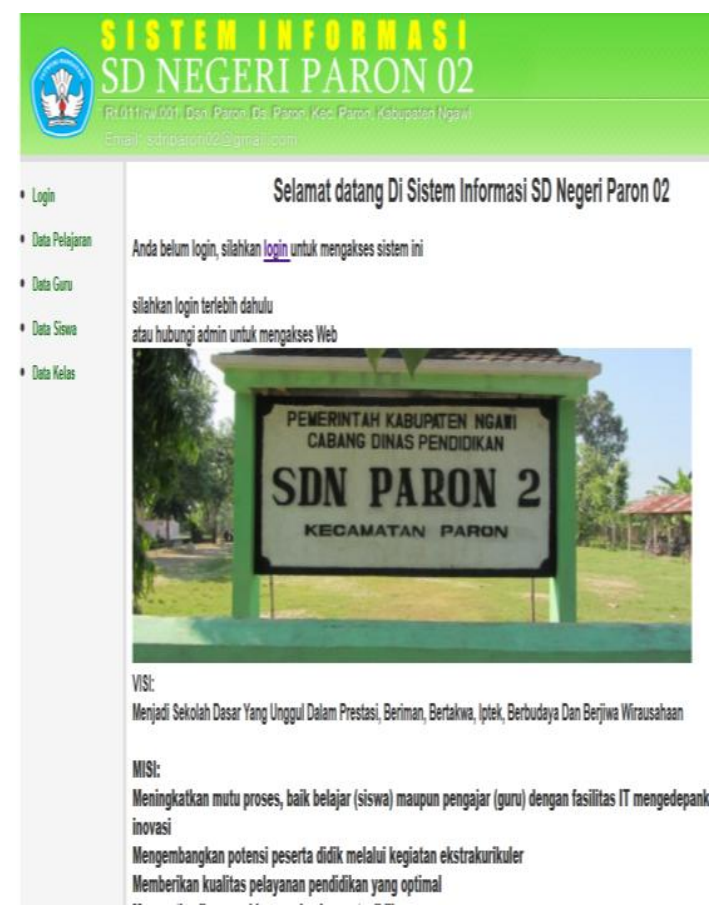

Gambar 5. Implementasi Halaman Awal Sebagai User

Selanjutnya implementasi halaman data pelajaran sebagai user. Ketika memilih menu data pelajara maka, user hanya dapat melihat no, kode, nama pelajaran, dan keterangan. Seperti pada tampilan Gambar 6.

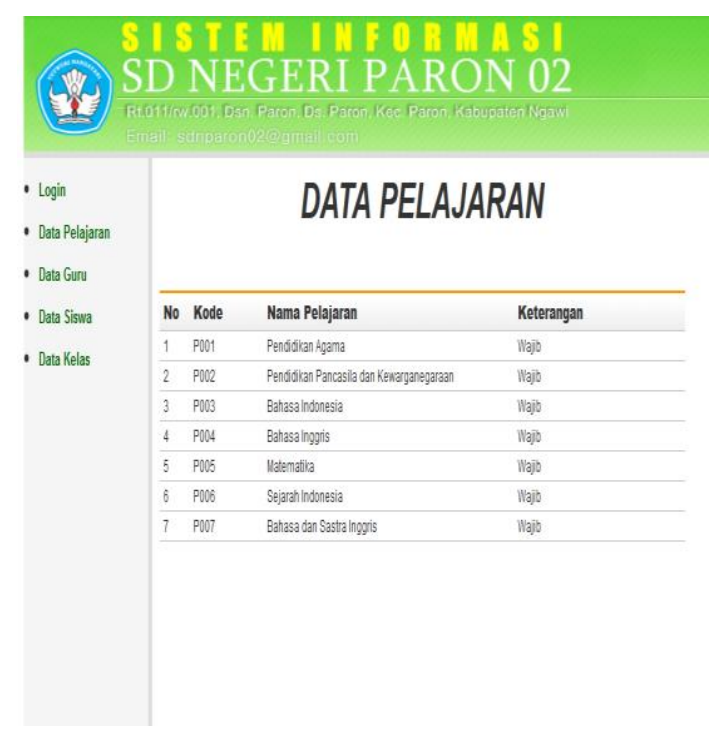

Gambar 6. Implementasi Halaman Data Pelajaran Sebagai User.

Selanjutnya implementasi halaman data guru sebagai user. Ketika memilih menu data guru maka, user hanya dapat melihat no, kode, nip, nama guru dan kelamin. Seperti pada tampilan Gambar 7.

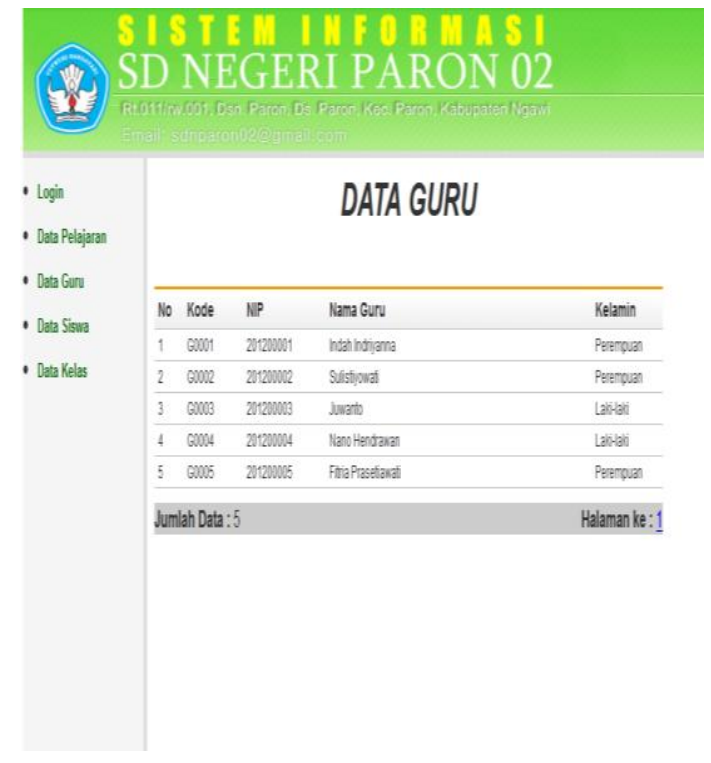

Gambar 7. Implementasi Data Guru Sebagai User

Selanjutnya implementasi halaman data siswa sebagai user. Ketika memilih menu data siswa maka, user hanya dapat melihat no, nis, nama siswa, kelamin, agama, tempat lahir, tanggal lahir, alamat, no. Telp, tahun angkatan dan status. Seperti pada tampilan Gambar 8 .

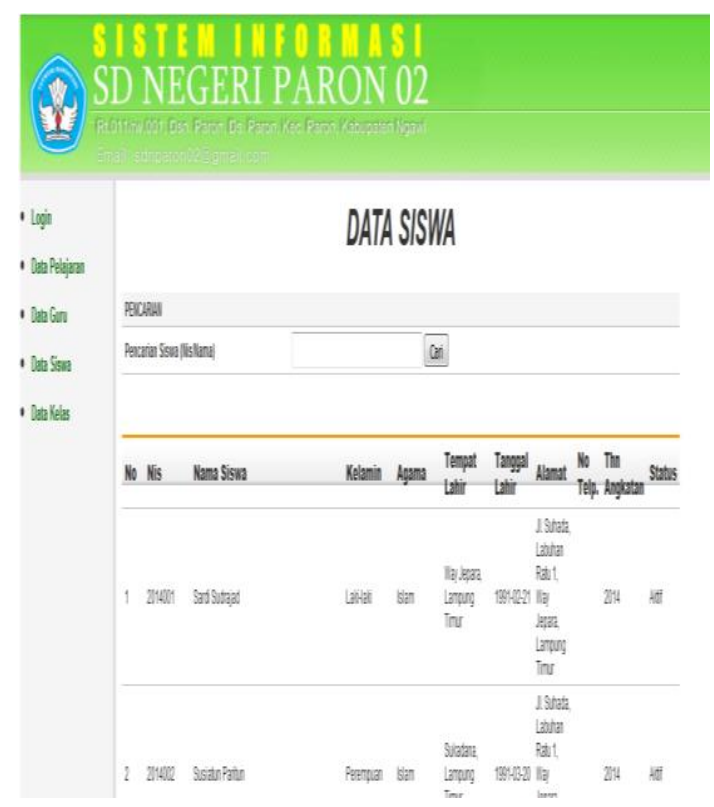

Gambar 8. Implementasi Data Siswa Sebagai User

Selanjutnya implementasi halaman data kelas sebagai user. Ketika memilih menu data kelas maka, user hanya dapat melihat no, kode, tahun ajaran, nama kelas, siswa dan wali kelas. Seperti pada tampilanGambar 9. 


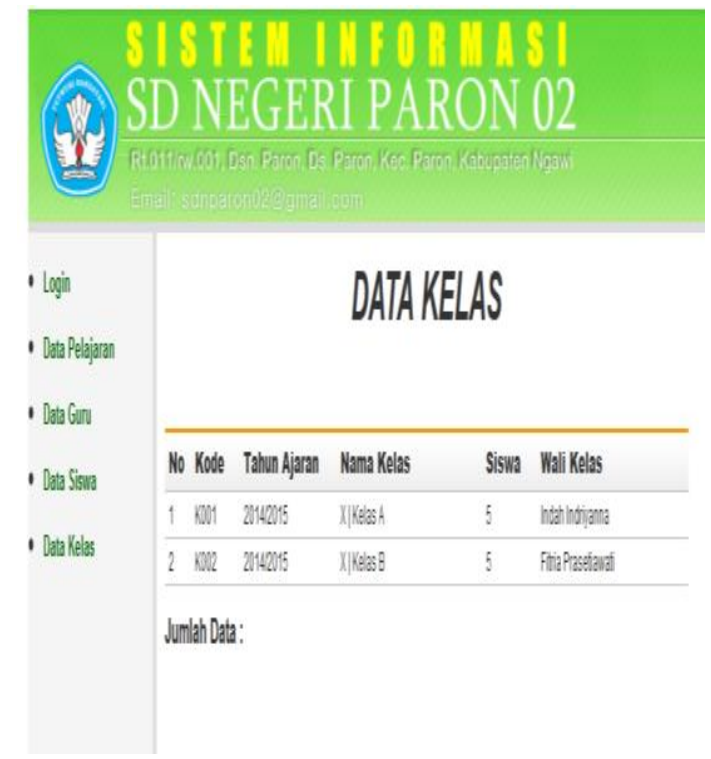

Gambar 9. Implementasi Data Kelas Sebagai User

Selain user, terdapat halaman admin. Untuk menjadi seorang admin harus melakukan login terlebih dahulu. Seperti pada tampilan Gambar 10.

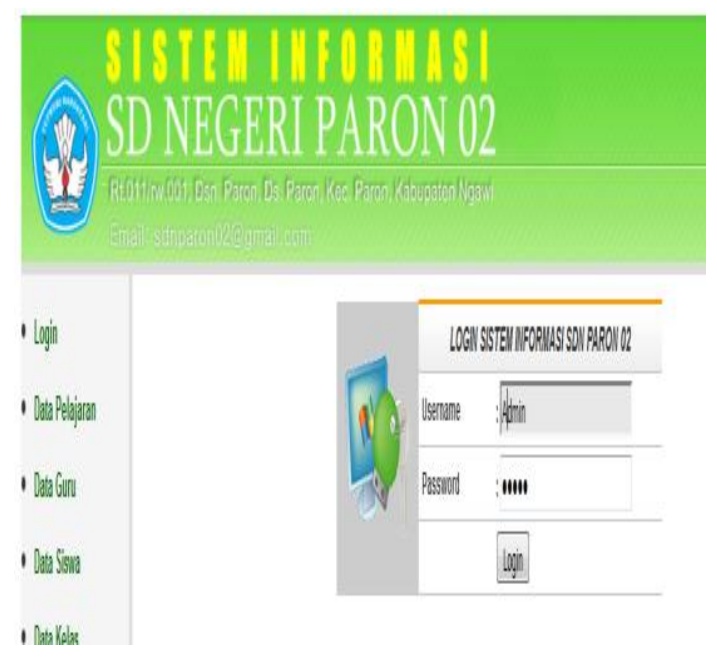

Gambar 10. Implementasi Halaman Login

Selanjutnya implementasi halaman awal sebagai admin. Setelah melakukan login terdapat menu halaman awal, data userdata, pelajaran, data guru, data siswa data kelas dan logout. Seperti pada tampilan Gambar 11.

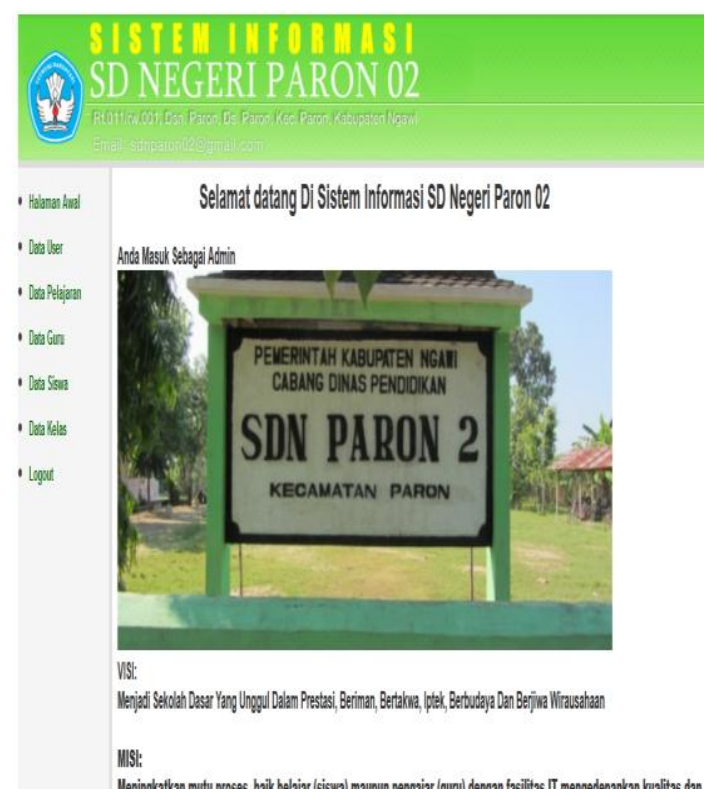

Gambar 11. Implementasi Halaman Awal Sebagai Admin

Selanjutnya implementasi halaman data user. Ketika memilih menu data user maka, admin dapat mengelola data, kode, nama user, username. Seperti pada tampilan Gambar 12.

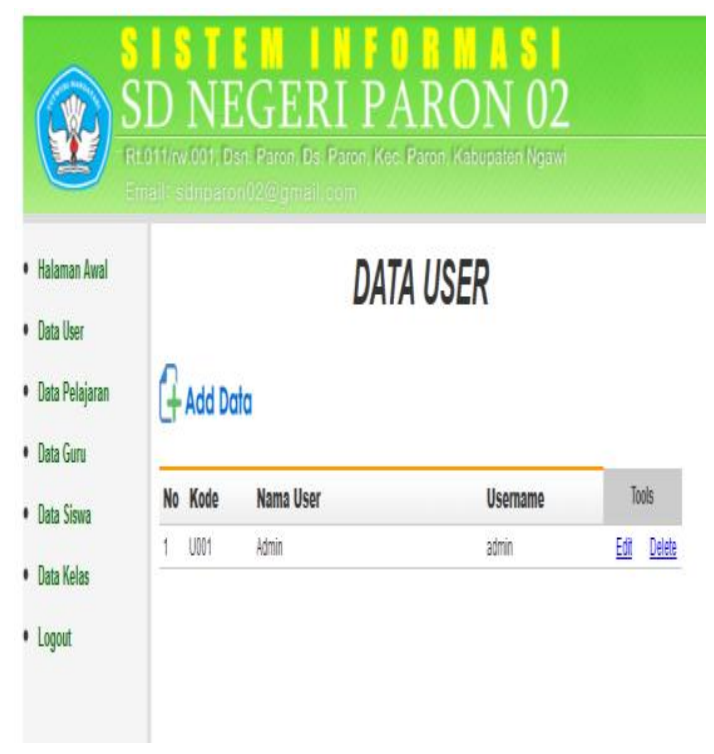

Gambar 12. Implementasi Halaman User Sebagai Admin

Selanjutnya implementasi halaman data pelajaran. Ketika memilih menu data pelajaran maka, admin dapat mengelola no, kode, nama pelajaran dan keterangan Seperti pada tampilan Gambar 13. 


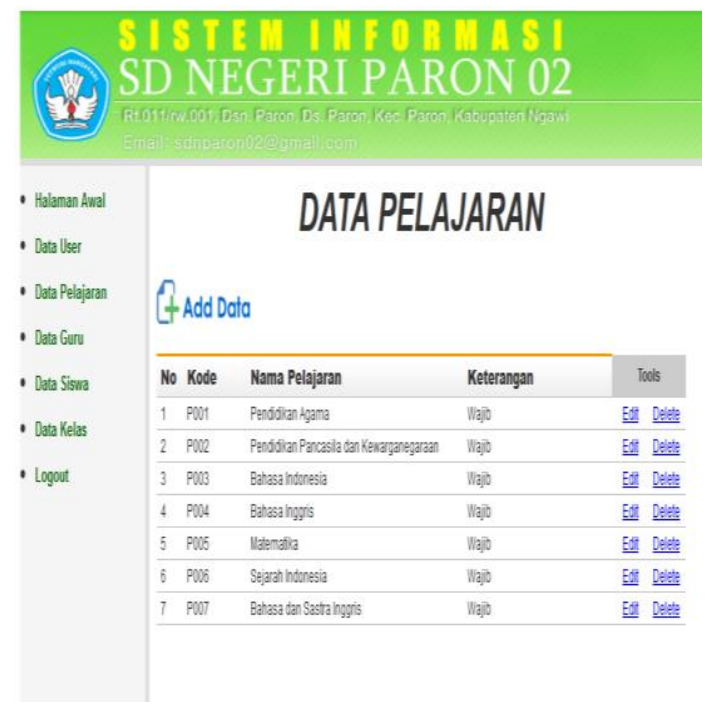

Gambar 13. Implementasi Halaman Data Pelajaran Sebagai Admin

Selanjutnya implementasi halaman data guru sebagai adnin. Ketika memilih menu data guru maka, Admin dapat mengolah no, kode, nip, nama guru dan kelamin. Seperti pada tampilan Gambar 14.

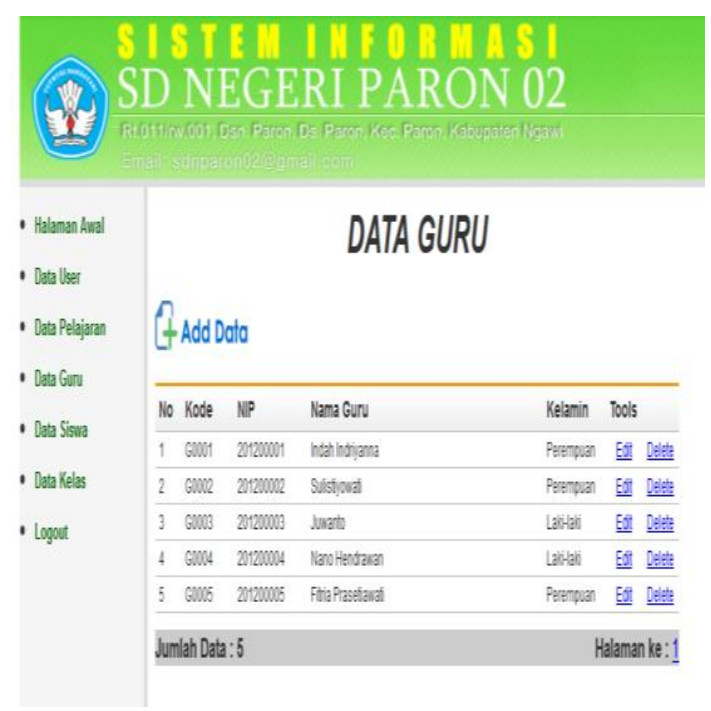

Gambar 14. Implementasi Halaman Data Guru Sebagai Admin

Selanjutnya implementasi halaman data siswa sebagai admin. Ketika memilih menu data siswa maka, admin dapat mengelola no, nis, nama siswa, kelamin, agama, tempat lahir, tanggal lahir, alamat, no. Telp, tahun angkatan dan status. Seperti pada tampilan Gambar 15.

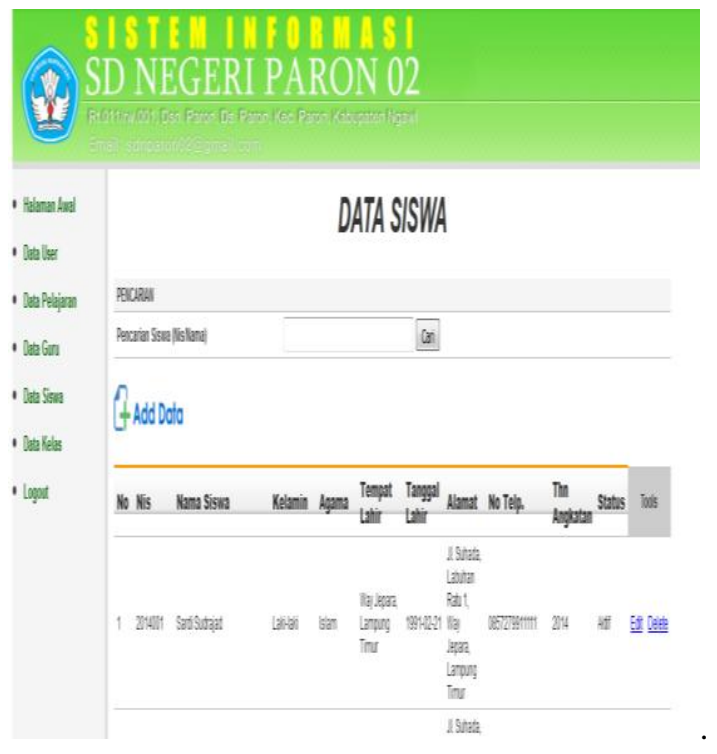

Gambar 15. Hamalan Implementasi Data Siswa Sebagai Admin

Selanjutnya implementasi halaman data kelas sebagai admin. Ketika memilih menu data kelas maka, admin dapat mengelola no, kode, tahun ajaran, nama kelas, siswa dan wali kelas. Seperti pada tampilan Gambar 16.

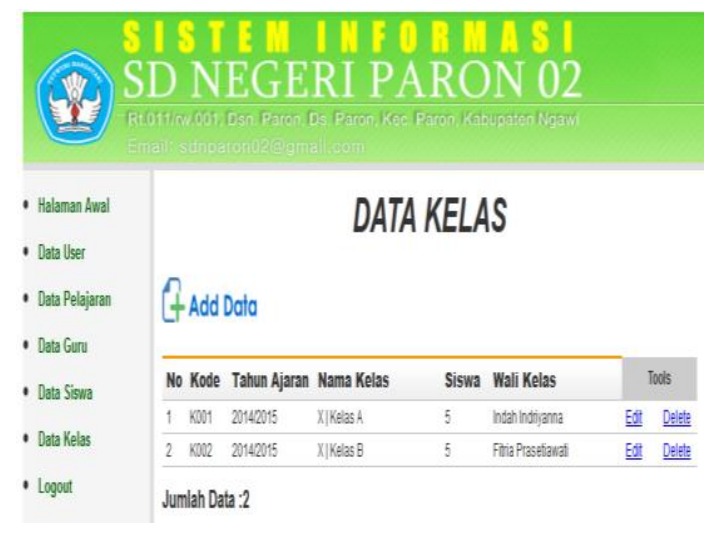

Gambar 16. Implementasi Halaman Data Kelas Sebagai Admin

\section{KESIMPULAN}

Berdasarkan uraian penelitian di atas, dapat disimpulkan bahwa telah berhasil dibangun Sistem Informasi SDN Paron 02 berbasis web. Dimana website tersebut berfungi untuk memberikan informasi kepada pengunjung web mengenai informasi sekolah.

\section{DAFTAR PUSTAKA}

Hasan,Lukman. 2014. Pengembangan Sistem Informasi Kearsipam Tata Usaha Menggunakan Metode Agile di MTS Arrosydin Secang Magelang. Yogyakarta: Universitas Sunan Kalijaga.

Hasibuan,Malayu S.P. 2008.Manajemen Sumber Daya Manusia. Jakarta: PT Bumi Aksara.

Romadhoni E.N.A., dkk. 2015. Implementasi Model Waterfall Pada Pengembangan Sistem Informasi 
Alumni SMKN 1 Jenangan Ponorogo. Universitas Negri Malang. Seminar Nasional Sistem Informasi Indonesia.

Dermawan,Juniardi., Hartini,Sari. 2017. Implementasi Model Waterfall Pada Pengembangan Sistem Informasi Perhitungan Nilai Mata Pelajaran Berbasis Web Pada Sekolah Dasar Al-Azhar Syifa Budi Jatibening. Jurnal Pradigma. Vol.19.No.2. p- ISSN 1410-5063.,eISSN 2579-3500.

Recky T. D,dkk. 2015. Perancangan Sistem Informasi Akademik Sekolah Berbasis Web Studi Kasus Sekolah Menengah Atas Kristen 1 Tomohon.ISSN 2301-8402.
Rahmawati,lina. 2012. Perancangan Website Sebagai Sarana Promosi Pada MTs MA'Arif NU 1 Ajibarang. STIMIK Amikom. Purwokerto. Vol.15 .No2

Rahmad,M.A. 2013. Sistem Informasi Berbasis Web Untuk Menunjang Promosi Jasa GBU18Studio. Universitas Dian Nuswantoro. Semarang.

Hartiwi,Yessi. 2017. Analisis dan Implementasi Sistem Informasi Penjualan Berbasis Web Pada Scarlet

Jogiyanto,HM. 2005. Analisis dan Design Sistem Informasi Pendekatan Terstruktur dan Aplikasi Bisnis. , Edisi pertama Cetakan Ke 4, Andi Yogyakarta. 